\title{
A mixed-methods exploration of implementation of a comprehensive school healthy eating model one year after scale-up
}

\author{
Patti-Jean Naylor ${ }^{1, *}$, Heather A McKay ${ }^{2}$, Maria Valente ${ }^{3}$ and Louise C Mâsse ${ }^{3}$ \\ ${ }^{1}$ School of Exercise Science, Physical and Health Education, University of Victoria, Box 3015, STN CSC, Victoria, BC \\ V8W 3P1, Canada: ${ }^{2}$ Department of Family Practice and Department of Orthopedics, Centre for Hip Health and \\ Mobility, University of British Columbia, Vancouver, British Columbia, Canada: ${ }^{3}$ Department of Pediatrics and \\ School of Population and Public Health, Centre for Community Child Health Research, University of British Columbia, \\ Vancouver, British Columbia, Canada
}

Submitted 28 November 2013: Final revision received 11 December 2014: Accepted 16 March 2015: First published online 20 May 2015

\begin{abstract}
Objective: To study the implementation of a school-based healthy eating (HE) model one year after scale-up in British Columbia (BC). Specifically, to examine implementation of Action Schools! BC (AS! BC) and its influence on implementation of classroom HE activities, and to explore factors associated with implementation. Design: Diffusion of Innovations, Social Cognitive and Organizational Change theories guided our approach. We used a mixed-methods research design including focus group interviews (seven schools, sixty-two implementers) and a cross-sectional multistage survey to principals ( $n$ 36, $92 \%$ response rate) and teachers of grades 4 to 7 ( $n$ 168, $70 \%$ response rate). Self-reported implementation of classroom HE activities and reported use of specific AS! BC HE activities were primary implementation measures. Thematic analysis of focus group data and multilevel mixed-effect logistic regression analyses of survey data were conducted. Setting: Elementary schools across BC, Canada.

Subjects: Thirty-nine school districts, thirty-six principals, 168 grade 4 to 7 teachers. Results: Forty-two per cent of teachers in registered schools were implementing AS! BC HE in their classrooms. Users were $6 \cdot 25$ times more likely to have delivered a HE lesson in the past week. Implementation facilitators were school champions, technical support and access to resources; barriers were lack of time, loss of leadership or momentum. Implementation predictors were teacher training, selfefficacy, experience with the physical activity component of AS! BC, supportive school climate and parental post-secondary education.

Conclusions: Our findings reinforce that continued teacher training and support are important public health investments that contribute to successful implementation of school-based HE models after scale-up.
\end{abstract}

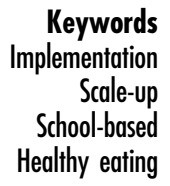

Environments and lifestyles have undergone visible changes in recent decades. Indeed, these changes have been implicated in the epidemic of physical inactivity and unhealthy eating habits that contribute to obesity and chronic disease risk $^{(1-4)}$. Specific dietary culprits are consumption of non-nutritious energy-dense foods and beverages, increased portion sizes, low fruit and vegetable intake, eating away from home and consuming convenience/fast food at home. Overall these factors contribute to increased energy intake ${ }^{(3)}$. The health consequences of these changes are substantive and beginning in childhood have been associated with decreases in quality of life ${ }^{(5)}$, increases in overweight/obesity ${ }^{(6)}$ and increased chronic disease risk $^{(7-10)}$. Thus, it seems imperative to address these modifiable dietary factors during childhood as one means to counter these disturbing public health trends.

Schools are popular settings for healthy eating (HE) interventions as children from across social strata spend considerable time in school and consume at least one meal or snack there ${ }^{(11,12)}$. Further, schools traditionally provide nutrition education to students ${ }^{(13)}$. Finally, schools represent natural 'settings' where interventions can be targeted across multiple levels, from the student to the global school environment ${ }^{(12,14)}$.

School-based HE interventions, especially those that incorporate environmental strategies, have had modest positive impacts on knowledge and eating behaviours ${ }^{(14-18)}$. 
Thus they are a recommended component of public health action for young people ${ }^{(11)}$. To take meaningful action we need to better understand how effective preventive health interventions can be scaled up, implemented and sustained to achieve desired outcomes ${ }^{(19-24)}$. Key aspects of diffusion of innovations (innovation characteristics) ${ }^{(25-28)}$, social cognitive (adopter/teacher) ${ }^{(25,27,28)}$, social marketing ${ }^{(29)}$ and organizational theory (organization/school) ${ }^{(25-32)}$ have been key to successful implementation over the short (efficacy trials) or long term (maintenance/sustainability trials). Planning for the state-wide scale-up of the Child and Adolescent Trial for Cardiovascular Health (CATCH) in Texas ${ }^{(29)}$ identified the importance of factors such as networks, cost, training, ongoing support, targeted approaches and the importance of both supporting and examining implementation after adoption. However, we know relatively little about factors that influence implementation of school HE interventions after scale-up in real-world settings; this deficit must be overcome to enhance the effectiveness of target interventions ${ }^{(33-37)}$.

Currently being implemented in British Columbia (BC), Canada, Action Schools! BC (AS! BC) is a comprehensive school health-based model that engages elementaryschool stakeholders and supports their capacity to create individualized action plans to enhance HE and physical activity (PA) opportunities for children. The model targets six key 'zones' for action: (i) the environment (including policies); (ii) the classroom; (iii) physical education; (iv) extra-curricular; (v) school spirit; and (vi) family and community $^{(31)}$. The PA and HE components of the overall model were developed, evaluated and scaled up using a phased approach (starting with PA). The PA model was designed and evaluated during the first phase and after demonstrating efficacy ${ }^{(4,31,32,38)}$ was scaled up in the 2004-05 school year. Then, after the feasibility and efficacy of the $\mathrm{HE}$ component were demonstrated $(2006-07)^{(39)}$, it was integrated into the AS! BC model and scaled up in the autumn of 2007 (Phase II).

Scale-up was planned and implemented by a central management team and technical support unit that shoulders an array of duties including: working with stakeholders; marketing the initiative; registering schools and teachers; preparing and supporting regional trainers ( $n$ 75) and two Master trainers; providing resources (HE 'bin' of equipment, materials and curriculum resources) and training for teachers and the school community; and providing direct email, telephone and web-based technical support to teachers and school administrators. An overview of the AS! BC HE intervention package, which has been described previously ${ }^{(39)}$, is summarized in Table 1.

Provincial scale-up of AS! BC HE presented us with the unique opportunity to assess implementation and the factors that influenced it after scale-up. Specifically, our study set out to: (i) identify the contextual factors that influenced implementation; (ii) describe implementation and its relationship with the provision of HE lessons in the classroom; and (iii) assess how the characteristics of the innovation, schools and teachers were hierarchically associated with implementation after scale-up.

\section{Experimental methods}

\section{Procedures}

The study was conducted according to the guidelines laid down in the Declaration of Helsinki and all procedures

Table 1 Key components of the Action Schools! BC (AS! BC) Healthy Eating (HE) intervention

\begin{tabular}{|c|c|}
\hline Dose/component & Description \\
\hline Dose & $\begin{array}{l}\text { The HE intervention included lessons and experiential activities for the classroom. In Phase I, teachers were } \\
\text { asked to provide two HE activities/week and one tasting activity/month in the classroom }{ }^{(39)} \text {. In Phase II, } \\
\text { based on formative evaluation results, three of the six Action Zones (School Environment, Classroom } \\
\text { Action, and Family \& Community) were emphasized and teachers were asked to implement one multi- } \\
\text { lesson Vegetable \& Fruit unit per term (i.e. two units/year), as well as a tasting activity every month and a } \\
\text { minimum of three other whole school community activities which included either activities that targeted the } \\
\text { school environment or activities that targeted the family and community zone (e.g. Fruit and Vegetable } \\
\text { Fridays) }\end{array}$ \\
\hline $\begin{array}{l}\text { Classroom HE Resource } \\
\text { (CHEAR) }\end{array}$ & A set of activities and lesson plans to help teachers plan classroom HE lessons and activities \\
\hline Action Pages! & A resource directory to link teachers with 'field tested' resources to use in their HE lessons and activities \\
\hline Classroom HE Action Pack & $\begin{array}{l}\text { A kit of HE equipment that supports classroom lessons and experiential activities like taste testing (e.g. } \\
\text { colanders, ice bags to keep vegetables cold, cutting boards and knives, placemats, food models, etc.) }\end{array}$ \\
\hline Support Team \& Training & $\begin{array}{l}\text { A central technical support unit provided the AS! BC HE resources (training workshops - one per school year, } \\
\text { written materials, Action Packs, school newsletter inserts for families, etc.), bi-monthly school visits from a } \\
\text { Master trainer and ongoing telephone support to school staff }\end{array}$ \\
\hline School Action Team & $\begin{array}{l}\text { A committee of school stakeholders (e.g. interested teachers, administrators, parents) helped to create a HE } \\
\text { Action Plan for the school and to support implementation }\end{array}$ \\
\hline $\begin{array}{l}\text { Whole School Community } \\
\text { Activities }\end{array}$ & $\begin{array}{l}\text { In addition to the classroom action zone, actions were planned across five other zones. The Family \& } \\
\text { Community zone involved activities such as healthy food fundraising and healthy school feasts. School-wide } \\
\text { events could be something like Fruit and Veg Fridays or a fruit and vegetable challenge. School environment } \\
\text { could include applying for the provincial school fruit and vegetable snack programme or planting a vegetable } \\
\text { garden }\end{array}$ \\
\hline
\end{tabular}


involving human subjects/patients were approved by both the Clinical Research Ethics Board at the University of British Columbia and the Human Research Ethics Board at the University of Victoria. Recruitment was conducted in the 2007-08 school year. We adopted the same recruitment protocols and data collection procedures that were used in the AS! BC PA implementation study ${ }^{(40)}$. Briefly, principals received a letter/email inviting them to participate. Volunteer schools supported recruitment by identifying a person who would act as the contact and study coordinator. These coordinators then distributed teacher invitations and collected the contact information of any volunteers. On data collection day the coordinator received and distributed a sealed package with a unique code and a web address link to an online questionnaire (Class Climate V5·1; Scantron Corporation) to each participant. We also funded a substitute teacher so that participants had time to complete the survey and provided honorariums. Focus groups were conducted during the school lunch period and lunch was provided.

\section{Research design and theoretical framework}

We used mixed methods to explore implementation after scale-up. We used a qualitative approach ${ }^{(41)}$ to explore contextual factors and as previously described by Mâsse et al., we used concepts from Rogers' Diffusion of Innovations, Social Cognitive and Organizational Change theories $^{(42-45)}$ to guide the quantitative examination of implementation and the hierarchy of theoretically derived influences on it $^{(40)}$. We analysed data from the qualitative and quantitative methods independently and integrated data during the interpretation stage ${ }^{(46)}$.

\section{Sample}

We obtained school district approval from thirty-five out of fifty-nine BC school districts (59\% response rate; excluding three school districts that piloted the survey). For the qualitative evaluation of contextual factors that influenced implementation, we purposively selected seven schools that were implementing AS! BC HE in the first year of scale-up and represented a broad range of school types and geographic locations. Sixty-two staff across seven schools participated in focus groups. For the quantitative evaluation of implementation that examined the hierarchy of factors influencing implementation, we conducted a cross-sectional multistage survey of school principals and teachers of grades 4 to 7 in BC (2008-09 school year). All schools that received training to deliver AS! BC HE, during the 2007-08 school year, were eligible to participate. Exclusion criteria included pilot, Independent, Francophone and First Nations schools. Of the eighty-eight eligible schools, thirty-nine agreed to participate ( $44 \%$ response rate). Within participating schools, $36 / 39$ principals ( $92 \%$ response rate) and $168 / 238$ grade 4 to 7 teachers ( $70 \%$ response rate) completed the survey.

\section{Instruments}

Implementation context

We explored implementation qualitatively using semistructured focus group interview questions that addressed different aspects of the AS! BC HE model: (i) its influence within the school and community; (ii) the response of teachers and administrators in the school; (iii) implementation challenges; and (iv) facilitators and changes necessary to sustainability.

\section{Implementation}

We assessed 'current use of the AS! BC HE model' using a seven-item measure modelled after the Steckler et al. current use questions ('yes'/'no') ${ }^{(47)}$. For the quantitative analyses, items were dichotomized to determine whether teachers were current users or not of the model. Non-users represented those who said they never used the model, were contemplating or preparing to use the model, or reported they had used the model in the previous school year but were not current users. In contrast, users represented those who indicated using the model in the current school year no matter what frequency and duration of use. Validity of this dichotomous index was assessed by correlating it with a measure that assessed whether the teachers were using specific AS! BC HE materials and resources (Pearson correlation $=0 \cdot 50$ ).

We assessed implementation as 'classroom delivery of HE lessons/activities', by asking (i) how many times in the past week teachers had incorporated HE lessons or activities into their class routine (0-7) and (ii) whether they had used or displayed (in the past or recently) instructional resources and materials, tracked consumption, prepared and/or tasted fruit and vegetables or went on a field trip (yes/no). In each of these categories AS! BC HE users were asked about specific AS! BC promoted resources while non-users answered generic questions.

\section{Implementation factors; characteristics of schools, teachers and innovation}

We assessed 'organizational climate' with one item that asked principals whether HE was a priority for their school (5-point response ranging from 'strongly disagree' to 'strongly agree').

We assessed 'organizational capacity' with four items that asked school principals whether: (i) teachers had enough time to implement AS! BC; (ii) their schools had resources for the implementation of AS! BC; (iii) their schools had funds to support the implementation of AS! $\mathrm{BC}$; and (iv) they themselved were committed to provide the resources to the implementation of AS! BC (5-point response ranging from 'strongly disagree' to 'strongly agree'). Results from the factor analysis demonstrated that this scale measured one main dimension explaining $57.3 \%$ of the total variance with a Cronbach's $\alpha$ of $0 \cdot 80$.

We assessed 'level of institutionalization' with nine items that were modelled after Goodman et al.'s ${ }^{(48)}$ measure. 
The scale assessed whether the school had implemented guidelines and practices to ensure the uptake and implementation of AS! BC (i.e. made AS! BC part of school culture, established guidelines/policies, adapted the concepts to fit the schools and allocated resources to ensure uptake; 'yes'/ 'no' or 'yes, established clearly', 'yes, somewhat established' and 'no'). A weighted average was computed to account for the differences in response format. Results from the factor analysis demonstrated that this scale measured one main dimension explaining $35.7 \%$ of the total variance with a Cronbach's $\alpha$ of $0 \cdot 83$.

We assessed 'environmental influences' by measuring whether the school was in compliance with recent nutritional guidelines mandated by the Province level (equivalent of State level). Specifically, this item assessed the extent to which the schools had eliminated access to and availability of less healthful foods and beverages at school (vending machines, cafeteria and/or school store), for fundraising activities, at special school events or in the classroom ('yes, fully implemented', 'in the process of implementing' and 'no'). This index was dichotomized into yes/no for the analysis.

We assessed teacher 'self-efficacy' with seven items that were modelled after the Brenowitz and Tuttle scale ${ }^{(49)}$. The scale measured whether teachers: (i) understood the concepts of AS! BC; and (ii) had confidence in their skills, their ability to devote time and their ability to motivate and engage students in HE activities (5-point response ranging from 'strongly agree' to 'strongly disagree'). Results from the factor analysis demonstrated that this scale measured one main dimension explaining $51.2 \%$ of the total variance with a Cronbach's $\alpha$ of 0.88 .

We assessed 'behavioural capacity' of the teacher with two items. One item measured if the teacher received AS! BC training for HE ('yes'/'no'). One item measured whether the teachers were users of the AS! BC PA component.

We asssessed 'innovation attributes' using an elevenitem scale modelled after Rogers' adoption questions ${ }^{(47)}$ using a 5-point response format ranging from 'strongly agree' to 'strongly disagree'. We assessed whether teachers' perceived AS! BC HE to be: (i) advantageous compared with other initiatives; (ii) complex to use; (iii) compatable with their teaching philosophy; (iv) easy to try in their classroom; and ( $v$ ) if it created positive outcomes. Results from the factor analysis demonstrated that this scale measured one main dimension explaining $47.8 \%$ of the total variance with a Cronbach's $\alpha$ of 0.91 .

\section{Covariates}

We assessed the following variables as covariates: gender and teaching experience of teachers, urbanicity, size of school and percentage of the population around the school with post-secondary education. We obtained school-level covariates by linking the school postal code with information from the Ministry of Education and the 2006 Canadian Census.

\section{Statistical analyses}

\section{Qualitative data}

Upon completion of each focus group, we transcribed each audio recording verbatim and imported them into the software NVivo $2 \cdot 0$ for analysis. This allowed us to create a framework for organizing and theming data. Data were initially grouped into NVivo nodes based on the focus group questions. We conducted basic content analysis to examine the data for meaning. Text was grouped into preliminary categories, re-examined for recurring themes and relationships, and reduced into key themes and sub-themes ${ }^{(50)}$.

\section{Quantitative data}

We used the statistical software package Stata version 13.1 to generate descriptive characteristics of participants. We developed a mixed-effects logistic regression analysis to determine if implementation of $\mathrm{HE}$ activities was significantly associated with current use of AS! BC HE (described in the 'Instruments' section as a dichotomous indicator which assessed whether teachers were current users or not). We developed a multilevel mixed-effect logistic regression model to identify factors that influenced AS! BC HE implementation. To account for the nested structure of the data we developed a two-level effect model with schools and school districts entered as separate levels while attributes of the innovation, characteristics of the teachers (self-efficacy, training received and users of AS! BC) and characteristics of the schools (organizational climate, organizational capacity, level of institutionalization and environmental influences), teachers' covariates (gender and teaching experience) and school covariates (school size, percentage of the population with post secondary education and urbanicity) were entered as fixed effects. Our results report reqression coefficients, $95 \%$ confidence intervals and odds ratios which are estimated by exponentiating the estimated coefficient. We first examined univariate associations and then proceeded with a multivariable analysis where all variables were entered at once regardless of whether they were univariately significant. We opted to include all variables given the conceptual framework we tested ${ }^{(40)}$. We applied multiple imputation to accommodate for missing values among the independent variables, using twenty replicates and the iterative Markov chain Monte Carlo (MCMC) procedure.

\section{Results}

\section{Qualitative exploration of contextual factors that influenced implementation}

Focus group participants reported successfully implementing AS! BC HE in the first year after dissemination. At the school level four themes emerged regarding the benefits of implementing AS! BC HE: (i) enhanced community partnerships; (ii) links to more HE resources; (iii) creation of a HE culture in the school; and (iv) links to environmental 
initiatives within the school. At the student level teachers and administrators highlighted the positive impact on children's attitudes and behaviours. In the words of one teacher: 'It is getting children back to eating healthy foods, and if they see their teacher and their classmates doing it, sometimes, they'll be more open to try new things'.

Participants identified (i) having a school 'leader/ champion', (ii) support from the AS! BC central team and (iii) access to resources and funding as the top three implementation facilitators. Participants from some schools also indicated that community and school engagement supported their ability to successfully implement activities.

Conversely, implementation was not without challenges. Teachers and administrators cited 'lack of time' as the most common barrier. For instance, one teacher stated: 'To find the time... that was the biggest obstacle'. Other challenges noted were lack of resources, leadership and momentum. Related to resource limitation one teacher's quote highlighted how the cost of the Action Bin was problematic: 'I think the cost of the kits, we get one per grade level (free)... so if you have three classrooms at a grade level and we only have one kit and you have to buy one and they are 200 each, I think that is a challenge, somehow the cost has to be more reasonable'.

Lack of leadership caused by high staff turnover was another common theme. If staff champions or leaders of implementation moved away from the school there was often no one to spearhead the programme, '...there was no one to fill his position and I didn't know anything about it'. Finally, while the school staff found the programme exciting at first, it was difficult to sustain positive momentum going throughout the school year; as expressed by one participant: 'it was great to implement, people were excited, but then as you go in the year, it gets forgotten because there are other things'.

When asked about sustainability participants highlighted the need to educate and connect the parents: 'I really believe that we need to continue to focus on educating the parents because that is where the lunches are coming from'. Official integration of the AS! BC HE activities within the curriculum rather than implementation as an '...extra' was another theme. Similarly a participant suggested expansion of the AS! BC HE activities and highlighted the importance of keeping the HE model relevant, fresh and responsive to teachers' needs: 'I think the program is phenomenal in its infancy, but what I would like to see is more education... I would not like to do the same program year after year. I would like it stepped up to the next level. Like how to read food labels...'.

\section{Quantitative analysis of implementation}

\section{Sample characteristics}

We describe participating schools, principals and teachers in Table 2. Schools had an enrolment of 294 students on average and were mostly from census metropolitan areas
Table 2 Descriptive information about the British Columbia schools ( $n$ 38) and school principals ( $n$ 34) and teachers ( $n$ 164) who participated in the study (2008-2009)

Mean, 25th-75th

SD or $\%$ percentiles

\begin{tabular}{|c|c|c|}
\hline \multicolumn{3}{|l|}{ School demographics ( $n 38$ ) } \\
\hline \multicolumn{3}{|l|}{$\begin{array}{l}\text { School size represented by number of } \\
\text { students }(n 38)\end{array}$} \\
\hline Mean & 294.3 & $168-398$ \\
\hline SD & $158 \cdot 2$ & \\
\hline Range & $32-807$ & \\
\hline \multicolumn{3}{|l|}{$\begin{array}{l}\text { Percentage of the population with post- } \\
\text { secondary education }(n 38)\end{array}$} \\
\hline Mean & $32 \cdot 1$ & $27 \cdot 1-37 \cdot 1$ \\
\hline SD & $9 \cdot 0$ & \\
\hline Range & $6 \cdot 5-46 \cdot 2$ & \\
\hline \multicolumn{3}{|l|}{$\begin{array}{l}\text { Census metropolitan area and census } \\
\text { agglomeration influenced zones ( } n 37)\end{array}$} \\
\hline Census metropolitan area & $60 \cdot 5$ & \\
\hline $\begin{array}{l}\text { Tracted/non-tracted census } \\
\text { agglomeration }\end{array}$ & $13 \cdot 1$ & \\
\hline Strongly to weakly influenced zones & $26 \cdot 3$ & \\
\hline \multicolumn{3}{|l|}{ School principal characteristics $(n 34)$} \\
\hline \multicolumn{3}{|l|}{ Sex (n 33) } \\
\hline Female & $75 \cdot 8$ & \\
\hline Male & $24 \cdot 2$ & \\
\hline \multicolumn{3}{|l|}{ Administrative experience $(n 33)$} \\
\hline $1-5$ years of experience & 33.3 & \\
\hline $6-10$ years of experience & $18 \cdot 2$ & \\
\hline $11-15$ years of experience & $24 \cdot \overline{2}$ & \\
\hline $16-20$ years of experience & $18 \cdot 2$ & \\
\hline $20+$ years of experience & $6 \cdot 1$ & \\
\hline \multicolumn{3}{|l|}{ Ethnicity $(n 33)$} \\
\hline Caucasian & $90 \cdot 9$ & \\
\hline Others & $9 \cdot 1$ & \\
\hline \multicolumn{3}{|l|}{ Teacher characteristics ( $n$ 164) } \\
\hline \multicolumn{3}{|l|}{$\operatorname{Sex}(n 164)$} \\
\hline Female & 71.3 & \\
\hline Male & 28.7 & \\
\hline \multicolumn{3}{|l|}{ Teaching experience $(n 164)$} \\
\hline $1-5$ years of experience & $18 \cdot 3$ & \\
\hline $6-10$ years of experience & $25 \cdot 0$ & \\
\hline $11-15$ years of experience & $20 \cdot 7$ & \\
\hline $16-20$ years of experience & $16 \cdot 5$ & \\
\hline $20+$ years of experience & 19.5 & \\
\hline \multicolumn{3}{|l|}{ Ethnicity $(n 164)$} \\
\hline Caucasian & 85.4 & \\
\hline Chinese & 4.9 & \\
\hline South-East Asian & 3.0 & \\
\hline Other & $6 \cdot 7$ & \\
\hline
\end{tabular}

where $32 \%$ of the population had post-secondary education. Most principals and teachers were female ( $76 \%$ and $71 \%$, respectively) and Caucasian ( $91 \%$ and $85 \%$, respectively); administrative or teaching experience varied widely.

\section{Implementation}

On average $42 \%$ of teachers were using AS! BC HE in their classroom with 39\% providing classroom HE activities weekly and $28 \%$ providing these activities on a monthly basis. Among those who were using the model, $96 \%$ of teachers used the Classroom Action HE books and manuals, $83 \%$ used promotional resources, 75\% utilized instructional resources and $53 \%$ kept weekly logs. AS! BC 
Table 3 Comparing the number of Healthy Eating (HE) classroom lessons activities in the past week and use of classroom HE resources, activities and equipment among users and non-users of Action Schools! BC as reported 2008-2009

\begin{tabular}{|c|c|c|c|c|c|}
\hline Variable & Descriptor & Coefficient & $95 \% \mathrm{Cl}$ & OR & $P$ value \\
\hline $\begin{array}{l}\text { No. of HE lessons in the last } \\
\text { week }\end{array}$ & 0 v. 1 or 2 & $1 \cdot 832$ & $0.887,2.777$ & $6 \cdot 246$ & 0.000 \\
\hline Use of HE book resources & $\begin{array}{l}\text { e.g. Veggies and Fruit of BC booklet, } \\
\text { Canada's Good Guide, HE Calendar, etc. }\end{array}$ & $3 \cdot 351$ & $1.929,4.774$ & $28 \cdot 542$ & 0.000 \\
\hline $\begin{array}{l}\text { Tracked HE activities done with } \\
\text { students }\end{array}$ & & 0.413 & $-0.309,1.136$ & 1.512 & 0.262 \\
\hline $\begin{array}{l}\text { Displayed HE promotional } \\
\text { resources }\end{array}$ & e.g. posters & $1 \cdot 317$ & $0.495,2.139$ & 3.732 & 0.002 \\
\hline $\begin{array}{l}\text { Displayed HE instructional } \\
\text { resources }\end{array}$ & e.g. Rainbow of Choice or Is It Fruit poster & 1.428 & $0.648,2 \cdot 189$ & $4 \cdot 130$ & 0.000 \\
\hline Used cutting board & & $2 \cdot 321$ & $1.417,3.224$ & $10 \cdot 185$ & 0.000 \\
\hline Used measuring cups & & 2.072 & $1.217,2.927$ & 7.941 & 0.000 \\
\hline Used colander & & $2 \cdot 810$ & $1.726,3.895$ & $16 \cdot 616$ & 0.000 \\
\hline Used scrub brush & & $2 \cdot 262$ & $1 \cdot 164,3 \cdot 360$ & $9 \cdot 604$ & 0.000 \\
\hline Used of peeler & & $2 \cdot 286$ & $1.256,3.316$ & 9.835 & 0.000 \\
\hline Used food group placemats & & 0.893 & $0.112,1.674$ & 2.442 & 0.025 \\
\hline $\begin{array}{l}\text { Used fruit and vegetable } \\
\text { placemats }\end{array}$ & & 1.560 & $0.559,2.562$ & $4 \cdot 761$ & 0.002 \\
\hline Used HE learning activities & Edible Plant Parts, Serving Size & $2 \cdot 068$ & $1.207,2.928$ & 7.907 & 0.000 \\
\hline Used HE tasting activities & Smoothies, BC Grown \& Ěat Your Colors & 1.328 & $0.508,2.15$ & 3.772 & 0.002 \\
\hline $\begin{array}{l}\text { Used snacking activities } \\
\text { HE field trips* }\end{array}$ & Healthy T Days, Crunch and Sip, ReThink Your Drink & $\begin{array}{l}2.294 \\
\text { n.d. }\end{array}$ & $\begin{array}{l}1.159,3.429 \\
\text { n.d. }\end{array}$ & $\begin{array}{l}9.924 \\
\text { n.d. }\end{array}$ & $\begin{array}{l}0.000 \\
\text { n.d. }\end{array}$ \\
\hline
\end{tabular}

${ }^{*}$ Due to the small number of responses $(n 4)$ we have not displayed the data.

provided equipment to schools to facilitate HE activities; $>50 \%$ of teachers used measuring cups (54\%) and cutting boards $(51 \%)$ while others used colanders $(47 \%)$ and peelers ( $40 \%)$. Interestingly, some teachers who did not formally adopt the AS! BC HE model used AS! BC instructional and promotion resources (43\%), equipment (10\%) and activities (11\%). Teachers who adopted the model were more likely to report having used HE related resources, activities and equipment (Table 3). Teachers' classroom tracking of $\mathrm{HE}$ activities was not significantly associated with use of AS! BC; $39 \%$ of those who adopted the model, compared with $36 \%$ of those who did not, reported tracking their classroom activities.

Use of AS! BC HE was strongly associated with the number of times teachers reported providing HE lessons or activities in the classroom in the last week $(P<0.001)$. Teachers who implemented the HE model were 6.25 (OR) times more likely to provide a HE lesson or activity compared with those who did not use the model. Forty-five per cent of those who adopted the HE model provided at least one HE activity per week compared with $16 \%$ of those who did not adopt the model.

\section{Implementation factors}

Organizational climate was conducive to implementation of the innovation. Among principals surveyed, $81 \%$ strongly agreed or agreed that HE was a top priority at their school; $86 \%$ reported that priority of HE had increased compared with three years previous. Approximately $51 \%$ of principals attributed this to both adopting and implementing AS! BC HE and the Provincial Guidelines for Food and Beverage Sales in the Schools. Almost $75 \%$ of principals reported that activities addressing the school environment (policy and physical environment changes) increased; $58 \%$ reported that family and community and $50 \%$ that school-wide activities also increased.

Among teachers, a significantly higher percentage of those who adopted AS! BC HE (27\%) noted that the overall initiative (AS! BC PA and HE) was a top priority in their school compared with only $12 \%$ of those who did not adopt the model $\left(\chi^{2}(2)=13.34, P=0.001\right)$. When asked whether HE was a priority at their schools, $89 \%$ and $85 \%$, respectively, believed that this priority had increased over the last three years. More than $50 \%$ of teachers at AS! $\mathrm{BC} \mathrm{HE}$ registered schools received training to deliver the model; $73 \%$ of them had previously adopted AS! BC PA. Teachers demonstrated moderately high self-efficacy (3.5/5) and relatively high positive perceptions of the attributes of the innovation (Table 4).

Univariable analyses are shown in Table 5. Two covariates were positively associated with use and appear to relate to each other. Larger schools were less likely to be users and schools in the least urbanized areas were more likely to be users than all other census conglomerations combined. Interestingly, use was more likely if school principals felt strongly that the climate of their school was not supportive of HE or conversely less likely if principals strongly agreed or agreed that their climate for HE was positive. Teachers who had high self-efficacy were more likely to be users as were those who used AS! BC PA, received $\mathrm{HE}$ training and had more positive perceptions regarding the attributes of the innovation.

The multivariable analysis displayed in Table 6 showed that the covariate (larger school size) identified in 
Table 4 Descriptive information for the underlying factors hypothesized to be associated with uptake of Action Schools! BC as reported in 2008-2009

\begin{tabular}{|c|c|c|}
\hline & $\begin{array}{l}\text { Mean, SD } \\
\quad \text { or } \%\end{array}$ & $\begin{array}{l}\text { 25th-75th } \\
\text { percentiles }\end{array}$ \\
\hline \multicolumn{3}{|c|}{ Characteristics of the schools ( $n 38)$} \\
\hline \multicolumn{3}{|c|}{ Organizational climate/support ( $n$ 33) } \\
\hline Strongly disagree & $3 \cdot 0$ & \\
\hline Disagree & $6 \cdot 1$ & \\
\hline Neither & $9 \cdot 1$ & \\
\hline Agree & $60 \cdot 6$ & \\
\hline Strongly agree & $21 \cdot 2$ & \\
\hline \multicolumn{3}{|c|}{ Organizational capacity/resources ( $n$ 33) } \\
\hline \multicolumn{3}{|c|}{ Percentage of dedicated } \\
\hline \multicolumn{3}{|c|}{ Physical Education specialists } \\
\hline Mean & 3.68 & $3 \cdot 25-4 \cdot 25$ \\
\hline SD & 0.89 & \\
\hline Range & $1 \cdot 75-5 \cdot 00$ & \\
\hline \multicolumn{3}{|c|}{ Level of institutionalization ( $n$ 31) } \\
\hline Mean & $6 \cdot 87$ & $5.50-8.50$ \\
\hline SD & 1.97 & \\
\hline Range & $3-10$ & \\
\hline \multicolumn{3}{|c|}{ Environmental influences ( $n$ 33) } \\
\hline High & $81 \cdot 8$ & \\
\hline Low & $18 \cdot 2$ & \\
\hline \multicolumn{3}{|c|}{ Characteristics of the teachers ( $n$ 164) } \\
\hline \multicolumn{3}{|c|}{ Self-efficacy $(n$ 162) } \\
\hline Mean & 3.54 & $3 \cdot 14-4.00$ \\
\hline SD & 0.68 & \\
\hline Range & $1.00-5 \cdot 00$ & \\
\hline \multicolumn{3}{|c|}{ Users of AS! BC PA ( $n$ 164) } \\
\hline Yes & $72 \cdot 6$ & \\
\hline No & $20 \cdot 6$ & \\
\hline \multicolumn{3}{|l|}{ Training ( $n$ 164) } \\
\hline Yes & $50 \cdot 6$ & \\
\hline No & $49 \cdot 4$ & \\
\hline \multicolumn{3}{|c|}{ Attributes of the innovation ( $n 587$ ) } \\
\hline \multicolumn{3}{|c|}{ Attributes of AS! BC $(n$ 158) } \\
\hline Mean & 3.77 & $3 \cdot 50-4 \cdot 13$ \\
\hline SD & 0.66 & \\
\hline Range & $1.00-5.00$ & \\
\hline
\end{tabular}

AS! BC PA, Action Schools! BC Physical Activity.

the univariable analysis did not remain significantly associated with implementation but that schools in neighbourhoods characterized by higher levels of postsecondary education were less likely to be users. Similarly only the multivariate analysis showed use was lower in schools where the principals strongly agreed or agreed that that the climate was supportive of HE. Higher teacher self-efficacy, having AS! BC HE training and using AS! BC PA were significant factors in the univariable analysis and remained so in the multivariate model, while positive perceptions of the innovation were no longer significant.

\section{Discussion}

We were provided the unique opportunity to assess factors that influenced implementation following a provincial scale-up (equivalent of state level) of an evidence-based, comprehensive, whole-school HE model (AS! BC HE).
The public health importance of evaluating the factors that influence successful implementation of effective prevention and health promotion programmes for children and youth has been very elegantly addressed in a systematic review by Durlak and DuPre ${ }^{(21)}$, who examined 542 interventions that focused across a wide range of topics (including physical health and academic performance). In that review, higher levels of implementation led to outcomes with mean effect sizes two to three times higher compared with studies where implementation was poor. Importantly, they found that perfect or near-perfect implementation of any intervention was unrealistic. Positive results were achieved at about $60 \%$ of desired implementation levels, with very few studies achieving more than $80 \%{ }^{(21)}$. In our study implementation was also not perfect. In the first year after scale-up just under half of teachers in registered schools identified themselves as users of the model. However, more than $60 \%$ of those were using the model (materials and activities) weekly or monthly. Importantly, teachers who implemented the AS! BC model were more likely to deliver HE lessons or activities in the classroom and this is an important determinant of student-level outcomes ${ }^{(21)}$.

Barriers to implementation included lack of time (the most common barrier), lack of leadership (loss due to staff turnover) and loss of momentum. Facilitators were support from a technical unit (including training) and access to resources (materials and funding: all resources were provided free for the school through provincial funding). These operational factors have been identified consistently in the school health literature ${ }^{(31,34,35,51-56)}$. Durlak and DuPre characterized leadership, access to resources (funding), time and loss of momentum due to competing demands in their broader implementation framework as delivery system factors ${ }^{(21)}$.

Training is recognized as a key issue identified in the efficacy, effectiveness, institutionalization/maintenance and dissemination literature ${ }^{(29,34,37,52,53,57)}$. This issue was not identified in our qualitative data most likely because a mechanism was in place for schools to access ongoing AS! $\mathrm{BC}$ training and we were talking to school staff who had received the training. However, participants suggested further training as a way to maintain momentum.

Our approach was embedded in diffusion of innovations, social cognitive and organizational change theories and assessed factors associated with these theories. Interestingly, training emerged as a significant teacherlevel factor in our quantitative analyses. Two other teacher-level characteristics that influenced implementation, experience implementing a similar model (AS! BC PA) and self-efficacy, also theoretically relate to training. Our findings uphold the tenets of social cognitive theory and speak to the importance of investing in teachers as key delivery agents for health promotion in elementary schools. If a teacher was trained to deliver HE activities, had previous experience and training to deliver a similar 
Table 5 Univariable results: characteristics of schools and teachers as well as attributes of the innovation and covariates associated with implementation of Action Schools! BC

\begin{tabular}{|c|c|c|c|c|}
\hline & Coefficient & $95 \% \mathrm{Cl}$ & OR & $P$ value \\
\hline \multicolumn{5}{|l|}{ Covariates (school level) } \\
\hline School size & -0.004 & $-0.007,-0.001$ & 1.00 & 0.016 \\
\hline Percentage of the population with post-secondary education & -0.009 & $-0.075,0.056$ & $0.99 \dagger$ & 0.781 \\
\hline \multicolumn{5}{|c|}{ Census metropolitan area and census agglomeration influenced zones } \\
\hline Tracted/non-tracted agglomeration v. metropolitan area* & -0.325 & $-1.870,1.219$ & 0.72 & 0.680 \\
\hline Strongly to weakly influenced zones $v$. metropolitan area* & 1.008 & $-0.248,2 \cdot 264$ & $2 \cdot 74$ & 0.116 \\
\hline \multicolumn{5}{|l|}{ Covariates (teacher level) } \\
\hline Sex (female $v \cdot$ male $^{*}$ ) & 0.282 & $-0.519,1.082$ & 1.33 & 0.491 \\
\hline Teaching experience & 0.183 & $-0.080,0.446$ & $1 \cdot 20$ & 0.173 \\
\hline \multicolumn{5}{|l|}{ Characteristics of schools } \\
\hline Organizational climate & -0.365 & $-0.844,0.113$ & 0.69 & 0.134 \\
\hline Organizational capacity & -0.025 & $-0.655,0.605$ & 0.98 & 0.939 \\
\hline Level of institutionalization & 0.183 & $-0.093,0.459$ & $1 \cdot 20 \ddagger$ & 0.194 \\
\hline Environmental influences & -0.580 & $-1.671,0.512$ & 0.56 & 0.298 \\
\hline \multicolumn{5}{|l|}{ Characteristics of teachers } \\
\hline Self-efficacy & 1.636 & $0.914,2.359$ & $5 \cdot 14 \ddagger$ & 0.000 \\
\hline Users of AS! BC PA (users v. non-users*) & 1.960 & $0.960,2.959$ & $7 \cdot 10$ & 0.000 \\
\hline Training (yes $v . n o^{*}$ ) & 1.845 & $1.034,2.656$ & $6 \cdot 33$ & 0.000 \\
\hline \multicolumn{5}{|l|}{ Attributes of the innovation } \\
\hline Attributes of AS! BC & 1.373 & $0.571,2.175$ & $3.95 \ddagger$ & 0.001 \\
\hline
\end{tabular}

AS! BC PA, Action Schools! BC Physical Activity.

${ }^{*}$ Referent group.

†Incremental change of $10 \%$.

¥Comparing 25th and 75 th percentile scores.

Table 6 Multivariable results: characteristics of schools and teachers as well as attributes of the innovation and covariates associated with implementation of Action Schools! BC

\begin{tabular}{|c|c|c|c|c|}
\hline & Coefficient & $95 \% \mathrm{Cl}$ & OR & $P$ value \\
\hline \multicolumn{5}{|l|}{ Fixed-effects parameters } \\
\hline Constant & -1.963 & $-8.929,5.004$ & - & 0.0581 \\
\hline \multicolumn{5}{|l|}{ Covariates (school level) } \\
\hline School size & -0.001 & $-0.006,0.003$ & 0.90 & 0.555 \\
\hline Percentage of the population with post-secondary education & -0.119 & $-0.230,-0.009$ & $0.89 \dagger$ & 0.035 \\
\hline \multicolumn{5}{|c|}{ Census metropolitan area and census agglomeration influenced zones } \\
\hline Tracted/non-tracted agglomeration v. metropolitan area* & -0.968 & $-3.009,1.072$ & 0.38 & 0.352 \\
\hline Strongly to weakly influenced zones $v$. metropolitan area* & -0.285 & $-2.974,2.403$ & 0.75 & 0.835 \\
\hline \multicolumn{5}{|l|}{ Covariates (teacher level) } \\
\hline Sex (female $v$. male ${ }^{*}$ ) & 0.380 & $-0.642,1.403$ & 1.46 & 0.466 \\
\hline Teaching experience & 0.013 & $-0.324,0.350$ & 1.01 & 0.939 \\
\hline \multicolumn{5}{|l|}{ Characteristics of schools } \\
\hline Organizational climate & -0.794 & $-1.408,-0.181$ & 0.45 & 0.011 \\
\hline Organizational capacity & 0.199 & $-0.478,0.875$ & 1.22 & 0.564 \\
\hline Level of institutionalization & 0.114 & $-0.211,0.439$ & $1 \cdot 12 \ddagger$ & 0.492 \\
\hline Environmental influences & -0.959 & $-2.504,0.587$ & 0.38 & 0.224 \\
\hline \multicolumn{5}{|l|}{ Characteristics of teachers } \\
\hline Self-efficacy & 1.255 & $0.412,2.097$ & $3.51 \ddagger$ & 0.004 \\
\hline Users of AS! BC PA (users $v$. non-users*) & $1 \cdot 786$ & $0.570,3.002$ & 5.96 & 0.004 \\
\hline Training (yes $v$. no*) & 1.459 & $0.519,2.400$ & $4 \cdot 30$ & 0.002 \\
\hline \multicolumn{5}{|l|}{ Attributes of the innovation } \\
\hline Attributes of AS! BC & 0.662 & $-0.264,1.587$ & $1.94 \ddagger$ & 0.161 \\
\hline
\end{tabular}

AS! BC PA, Action Schools! BC Physical Activity.

${ }^{*}$ Referent group.

tIncremental change of $10 \%$.

¥Comparing 25 th and 75 th percentile scores.

health promotion activity (AS! BC PA) and/or believed $\mathrm{s} /$ he was able to do so, $\mathrm{s} /$ he was more likely to implement the innovation. These findings also reflect the importance of the training and support system that has been identified as a critical implementation factor in a broader review of implementation conducted by Durlak and DuPre ${ }^{(21)}$.
At the school level, school climate was the only significant factor but it emerged as a weak negative influence on implementation. This finding challenged our belief that a positive school climate for HE would positively influence adoption and implementation after scaleup. While counterintuitive at first, it may be that in schools 
where principals noted that HE was not a priority (which is how we operationalized school climate), they were more likely to adopt AS! BC HE as it would help them to address this need at their school. Furthermore, this finding would align with Riis et al. who noted that recent changes in school policies were more likely to occur in states were levels of obesity were higher ${ }^{(58)}$. This seems to align with our finding as HE was noted to be of high importance and this recognition probably encouraged schools where HE had not been a top priority to take action.

Based on the importance of the basic tenets of Diffusion of Innovations theory in the related literature, we anticipated that attributes of the innovation would also emerge as important. In fact, the univariable analysis supported this assumption while the multivariable did not. It may be that perceptions of the innovation were most influential at the early stage of adoption/registration. As teachers were confronted with implementation issues they may have become more influenced by factors such as training, experience and individual efficacy. Our cross-sectional study was not able to discern the specific answer to this question. However, longer-term prospective studies would shed more light on key factors related to implementation over time.

The broader school or community context influenced implementation. Teachers were more likely to implement the model if schools were in communities where residents had lower levels of education. Teachers in these communities may have perceived a greater need to deliver health-related programmes.

Although we did not initially set out to test an overarching implementation framework, our results highlight critical elements that have been identified in many ${ }^{(21,59)}$. Specifically, they highlighted the importance of community, delivery system (school level) and support system factors to implementation. Future research should integrate these frameworks in addition to existing theory to enhance our comprehensive understanding of implementation after scale-up.

Our findings must be interpreted in light of some limitations. First, we assessed implementation of HE lessons and activities broadly and of the AS! BC lessons/activities specifically, using self-report measures. To mitigate the limitations of our self-report instruments, we pilot tested and evaluated their psychometric properties in the larger sample. Second, as data are cross-sectional we are unable to differentiate factors that may influence implementation over time. Third, the sample size was limited given that we focused on schools that registered in AS! BC HE during the first year of scale-up and finally the school-level response rate was low, introducing the potential of a positive bias. However, when we compared the characteristics of the schools that participated in the study with the larger population of schools in the province, school size, percentage of the population with post-secondary education and geographic locations of schools were similar.
Finally, we would be remiss not to comment on the sociopolitical context for action as it is recognized as one community-level factor that influences implementation ${ }^{(21)}$. We introduced AS! BC into schools in BC during a time when the sociopolitical context was highly supportive. In 2006, BC won the bid to host the 2010 Winter Olympic Games. Government invested substantively in initiatives such as the scale-up of AS! BC to create the 'healthiest jurisdication to ever host the Olympic Games, ${ }^{(30)}$ and leave a legacy of health in the Province. In addition to supporting AS! BC, the BC Ministry of Education mandated guidelines for the sale of food and beverages in the school in 2008-09. Further, there was public support for action to encourage HE based on substantive media coverage related to the "childhood obesity epidemic'(30). Taken together these represent a powerful confluence of factors that would potentially impact school climate and enhance schools' readiness to make changes in their HE environment.

\section{Conclusion}

Our study extends the relatively meagre body of literature that has addressed implementation after scale-up of school-based health promotion programmes. Our findings reinforce that teacher training and support are important investments as they contribute to successful programme implementation. Further, resources must be provided, and school-level leadership nurtured, as they are also critical to sustained implementation after scale-up. Thus, public health and education decision makers should enact communication strategies that enhance the relevance of health promotion efforts to education stakeholders and support training and technical support for teachers and schools to ensure effective scale-up of health-related programmes. Finally, adopting an evidence-based approach to guide scale-up of effective school-based HE and PA interventions enhances the likelihood of a positive return on the investment in the health and well-being of our children.

\section{Acknowledgements}

Acknowledgements: The authors would like to thank Bryna Kopelow and Jennifer Fenton, the Action Schools! BC Support Team for their passion, commitment and leadership in all aspects of development, delivery and scaling up of the AS! BC model; and for survey development and to identify the sampling frame for this study. Finally, the authors owe a huge debt of gratitude to school administrators and teachers who contributed their valuable time to support this study. Financial support: This work was funded by the BC Ministry of Health and supported partially through the Canadian Institutes of Health Research (funding reference number GIR-86122) with joint funding 
from the Institute of Nutrition, Metabolism \& Diabetes and the Institute of Population \& Public Health. L.C.M. received salary support from the Michael Smith Foundation for Health Research (Senior Scholar), the Child and Family Research Institute and the Sunny Hill Foundation. The funders (BC Ministry of Health; Canadian Institutes of Health Research; Institute of Nutrition, Metabolism \& Diabetes; Institute of Population \& Public Health; Michael Smith Foundation for Health Research; Child and Family Research Institute; Sunny Hill Foundation) had no role in the design, analysis or writing of this article. Conflict of interest: None. Authorship: P.-J.N. and L.C.M. contributed equally. P.-J.N. was lead author. P.-J.N., L.C.M. and H.A.M. conceived and obtained funding to support the study. L.C.M., H.A.M. and M.V. edited the manuscript. M.V. and L.C.M. were primarily responsible for implementation of data collection. L.C.M. conducted the main analyses, prepared the tables and figures for the manuscript with support from M.V. All authors read and approved the manuscript. Ethics of buman subject participation: This study was conducted according to the guidelines laid down in the Declaration of Helsinki and all procedures involving human subjects/patients were approved by both the Clinical Research Ethics Board at the University of British Columbia and the Human Research Ethics Board at the University of Victoria.

\section{References}

1. Condon C (2006) The fat bomb exploded but no one heard the bang. Eur J Cardiovasc Nurs 5, 99-101.

2. Hill JO \& Melanson EL (1999) Overview of the determinants of overweight and obesity: current evidence and research issues. Med Sci Sports Exerc 31, 11 Suppl. S515-S521.

3. Institute of Medicine (2005) Preventing Childhood Obesity: Health in the Balance. Washington, DC: The National Acadamies Press.

4. Macdonald HM, Kontulainen SA, Petit MA et al. (2008) Does a novel school-based physical activity model benefit femoral neck bone strength in pre- and early pubertal children? Osteoporos Int 19, 1445-1456.

5. Wu XY, Ohinmaa A \& Veugelers PJ (2012) Diet quality, physical activity, body weight and health-related quality of life among grade 5 students in Canada. Public Health Nutr 15, 75-81.

6. Shields M (2006) Overweight and obesity among children and youth. Health Rep 17, issue 3, 27-42.

7. Plotnikoff RC, Karunamuni N, Spence JC et al. (2009) Chronic disease-related lifestyle risk factors in a sample of Canadian adolescents. J Adolesc Health 44, 606-609.

8. Lazarou C, Panagiotakos DB \& Matalas AL (2009) Lifestyle factors are determinants of children's blood pressure levels: the CYKIDS study. J Hum Hypertens 23, 456-463.

9. Moriarty-Kelsey M \& Daniels SR (2010) Childhood obesity is the fuel that fires adult metabolic abnormalities and cardiovascular disease. Child Obes 6, 250-256.

10. Harding S, Maynard MJ, Cruickshank K et al. (2008) Overweight, obesity and high blood pressure in an ethnically diverse sample of adolescents in Britain: the Medical Research Council DASH study. Int J Obes (Lond) 32, 82-90.

11. Wechsler H, Devereaux RS, Davis M et al. (2000) Using the school environment to promote physical activity and healthy eating. Prev Med 31, Suppl. 2, S121-S137.
12. Institute of Medicine (2012) Accelerating Progress in Obesity Prevention: Solving the Weight of the Nation. Washington, DC: The National Academies Press.

13. Carter MA \& Swinburn B (2004) Measuring the 'obesogenic' food environment in New Zealand primary schools. Health Promot Int 19, 15-20.

14. de Sa J \& Lock K (2008) Will European agricultural policy for school fruit and vegetables improve public health? A review of school fruit and vegetable programmes. Eur J Public Health 18, 558-568.

15. Knai C, Pomerleau J, Lock K et al. (2006) Getting children to eat more fruit and vegetables: a systematic review. Prev Med 42, 85-95.

16. Flynn MA, McNeil DA, Maloff B et al. (2006) Reducing obesity and related chronic disease risk in children and youth: a synthesis of evidence with 'best practice' recommendations. Obes Rev 7, Suppl. 1, 7-66.

17. Sharma M (2006) School-based interventions for childhood and adolescent obesity. Obes Rev 7, 261-269.

18. French SA \& Stables G (2003) Environmental interventions to promote vegetable and fruit consumption among youth in school settings. Prev Med 37, 593-610.

19. Glasgow RE (2008) What types of evidence are most needed to advance behavioral medicine? Ann Behav Med 35, 19-25.

20. Klesges LM, Dzewaltowski DA \& Glasgow RE (2008) Review of external validity reporting in childhood obesity prevention research. Am J Prev Med 34, 216-223.

21. Durlak JA \& DuPre EP (2008) Implementation matters: a review of research on the influence of implementation on program outcomes and the factors affecting implementation. Am J Community Psychol 41, 327-350.

22. Milat AJ, King L, Bauman AE et al. (2012) The concept of scalability: increasing the scale and potential adoption of health promotion interventions into policy and practice. Health Promot Int 28, 285-298.

23. Gugglberger L \& Dur W (2011) Capacity building in and for health promoting schools: results from a qualitative study. Health Policy 101, 37-43.

24. Rohrbach LA, Grana R, Sussman S et al. (2006) Type II translation: transporting prevention interventions from research to real-world settings. Eval Health Prof 29, 302-333.

25. Owen N, Glanz K, Sallis JF et al. (2006) Evidence-based approaches to dissemination and diffusion of physical activity interventions. Am J Prev Med 31, 4 Suppl. S35-S44.

26. Dunn AL \& Bettinghaus EP (2006) Diffusion and dissemination for increasing physical activity in world populations. Am J Prev Med 31, 4 Suppl. S94-S96.

27. Buller DB (2006) Diffusion and dissemination of physical activity recommendations and programs to world populations. Am J Prev Med 31, 4 Suppl. S1-S4.

28. Oldenburg B \& Parcel GGS (2002) Diffusion of innovations. In Health Behavior and Health Education, 2nd ed., pp. 312-334 [K Glanz, BK Rimer and BM Lewis, editors]. San Francisco, CA: Jossey-Bass.

29. Hoelscher DM, Kelder SH, Murray N et al. (2001) Dissemination and adoption of the Child and Adolescent Trial for Cardiovascular Health (CATCH): a case study in Texas. J Public Health Manag Pract 7, 90-100.

30. Naylor PJ, Macdonald HM, Reed KE et al. (2006) Action Schools! BC: a socioecological approach to modifying chronic disease risk factors in elementary school children. Prev Chronic Dis 3, A60.

31. Naylor PJ, Macdonald HM, Warburton DE et al. (2008) An active school model to promote physical activity in elementary schools: Action Schools! BC. Br J Sports Med 42, 338-343.

32. Reed KE, Warburton DE, Macdonald HM et al. (2008) Action Schools! BC: a school-based physical activity intervention designed to decrease cardiovascular disease risk factors in children. Prev Med 46, 525-531. 
33. Kumanyika S (2012) Raising the bar for research to lower the weight of the population. Health Educ Behav 39, 383-385.

34. Wiecha JL, El Ayadi AM, Fuemmeler BF et al. (2004) Diffusion of an integrated health education program in an urban school system: planet health. J Pediatr Psychol 29, 467-474.

35. Gittelsohn J, Merkle S, Story M et al. (2003) School climate and implementation of the Pathways study. Prev Med 37, 6 Pt 2, S97-S106.

36. Johnson CC, Li D, Galati T et al. (2003) Maintenance of the classroom health education curricula: results from the CATCH-ON study. Health Educ Behav 30, 476-488.

37. Lytle LA, Ward JL, Nader PR et al. (2003) Maintenance of a health promotion program in elementary schools: results from the Catch-on study key informant interviews. Health Educ Behav 30, 503-518.

38. Macdonald HM, Kontulainen SA, Khan KM et al. (2007) Is a school-based physical activity intervention effective for increasing tibial bone strength in boys and girls? J Bone Miner Res 22, 434-446.

39. Day ME, Strange KS, McKay HA et al. (2008) Action Schools! BC-Healthy Eating: effects of a whole-school model to modifying eating behaviours of elementary school children. Can J Public Health 99, 328-331.

40. Mâsse LC, McKay H, Valente M et al. (2012) Physical activity implementation in schools: a 4 -year follow-up. Am J Prev Med 43, 369-377.

41. Ryan F, Coughlan M \& Cronin P (2007) Step-by-step guide to critiquing research. Part 2: Qualitative research. Br J Nurs 16, 738-744.

42. Rimer BK, Glanz K \& Rasband G (2001) Searching for evidence about health education and health behavior interventions. Health Educ Behav 28, 231-248.

43. McKenzie TL, Li D, Derby CA et al. (2003) Maintenance of effects of the CATCH physical education program: results from the Catch-on Study. Health Educ Behav 30, 447-462.

44. Rogers EM (2003) Diffusion of Innovations, 5th ed. New York: Free Press.

45. Steckler A, Goodman RM \& Kegler MC (2002) Mobilizing organizations for health enhancement: theories of organizational change. In Health Behavior and Health Education, 2nd ed., pp. 335-360 [K Glanz, BK Rimer and BM Lewis, editors]. San Francisco, CA: Jossey-Bass.

46. Hanson WE, Creswell JW, Clark VLP et al. (2005) Mixed methods research designs in counseling psychology. J Couns Psychol 52, 224-235.
47. Steckler A, Goodman RM, McLeroy KR et al. (1992) Measuring the diffusion of innovative health promotion programs. Am J Health Promot 6, 214-224.

48. Goodman RM, McLeroy KR, Steckler AB et al. (1993) Development of level of institutionalization scales for health promotion programs. Health Educ $Q$ 20, 161-178.

49. Brenowitz N \& Tuttle CR (2003) Development and testing of a nutrition-teaching self-efficacy scale for elementary school teachers. J Nutr Educ Behav 35, 308-311.

50. Corbin J \& Strauss A (2008) Basics of Qualitative Research: Techniques and Procedures for Developing Grounded Theory, 3rd ed. Thousand Oaks, CA: SAGE Publications.

51. Dollahite J, Hosig KW, Adeletti White K et al. (1998) Impact of a school-based community intervention program on nutrition knowledge and food choices in elementary school children in rural Arkansas Delta. Health Educ Behav 30, 463-475.

52. Kelder SH, Mitchell PD, McKenzie TL et al. (2003) Longterm implementation of the CATCH physical education program. Health Educ Behav 30, 463-475.

53. Osganian SK, Parcel GS \& Stone EJ (2003) Institutionalization of a school health promotion program: background and rationale of the CATCH-ON study. Health Educ Behav 30, 410-417.

54. Story M, Mays RW, Bishop DB et al. (2000) 5-a-day Power Plus: process evaluation of a multicomponent elementary school program to increase fruit and vegetable consumption. Health Educ Behav 27, 187-200.

55. Weiss EH \& Kien CL (1987) A synthesis of research on nutrition education at the elementary school level. $J$ Sch Health 57, 8-13.

56. Singh AS, Chinapaw MJ, Brug J et al. (2009) Process evaluation of a school-based weight gain prevention program: the Dutch Obesity Intervention in Teenagers (DOiT). Health Educ Res 24, 772-777.

57. Hoelscher DM, Feldman HA, Johnson CC et al. (2004) School-based health education programs can be maintained over time: results from the CATCH Institutionalization study. Prev Med 38, 594-606.

58. Riis J, Grason H, Strobino D et al. (2012) State school policies and youth obesity. Matern Child Health J 16, Suppl. 1, S111-S118.

59. Damschroder LJ, Aron DC, Keith RE et al. (2009) Fostering implementation of health services research findings into practice: a consolidated framework for advancing implementation science. Implement Sci $\mathbf{4}, 50$. 